\title{
Effectiveness Of Mesotherapy In Treatment Of Fibromyalgia Tender Points
}

\author{
Refaat M. Eltanawy, Sahar S. Ganeb, Rasha M. Fawzy, Samia O. Ghorab
}

\begin{abstract}
Department of Rheumatology, Rehabilitation and Physical Medicine, Benha faculty of medicine, Benha University, Egypt
\end{abstract}

Correspondence to: Rasha M. Fawzy, department of Rheumatology, Rehabilitation and Physical Medicine, Benha faculty of medicine, Benha University, Egypt

Email:

dr.rasha.fawzy@hotmail.com

Received: 14 April 2020

Accepted: 11 May 2020

\begin{abstract}
Background: Fibromyalgia is the second most common disease encountered in rheumatology practice Aim: This study designed to assess the potential effect of mesotherapy in treatment of tender points in primary fibromyalgia (PFM) patients. Methods: Thirty PFM patients who fulfilled the American Colleague of Rheumatology 1990 criteria, joined this study. They were divided into 2 groups randomly according to the treatment program received; Injection mesotherapy group (Group $\mathbf{I}$ : $\mathrm{No}=15$ patients) who received a mixture of $2 \mathrm{ml}$ of Ketoprofen $(100 \mathrm{mg} / 2 \mathrm{ml})$ added to $3 \mathrm{ml}$ of Saline Solution, once cession per week for a total of 6 successive weeks and other 15 patients (Group II) who received Ketoprofen $100 \mathrm{mg}$ Extended- Release capsules once daily for 2 successive weeks which represent the control group. Patients' pain severity, quality of life and depression were assessed using visual analogue scale (VAS), fibromyalgia impact questionnaire (FIQ) and the Hamilton Rating Scale (HDRS) respectively before treatment and after the $3^{\text {rd }} \&$ the $6^{\text {th }}$ cession then data were recorded and compared. Results: We found significant improvements $(\mathrm{p}<0.001)$ tender point's number, VAS, FIQ and HDRS in the injection mesotherapy group compared to the control group with no major adverse effects were described.
\end{abstract}

Conclusion: This study supports the hypothesis that injection mesotherapy could offer a great therapeutic advantage in treatment of fibromyalgia tender points especially in the presence of associated comorbidities where there is a high risk of drug interaction, polypharmacy, or when conventional (oral or parenteral) NSAIDs use is contraindicated. 
Keywords: Mesotherapy, primary fibromyalgia, visual analogue scale (VAS), fibromyalgia impact questionnaire (FIQ), Hamilton Depression Rating Scale (HDRS).

\section{Introduction}

Fibromyalgia $(\mathrm{FM})$ is a non-inflammatory, chronic, widespread pain illness associated with a complex of symptoms as fatigue, depression, cognitive impairment, sleep disorders, and or emotional distress. It is the second most common disease encountered in rheumatology practice (1).

It causes a negative effect on the patient`s everyday activities, worsening the mood, impairing the relationships with the surrounding environment, affecting the capability to work and to be productive, and thus imposing huge financial burdens on the society and on the patient her/himself (2). Management of fibromyalgia requires a multidisciplinary approach, to address all the distressing symptoms, especially the pain, taking in consideration the multiple possible etiologies of the syndrome, altogether with the triggering factors (3).

50 years ago mesotherapy was presented by a French physician, Michel Pistor, who introduced this procedure as a new pain-relieving therapy for a diversity of rheumatologic complaints (4). It is an intradermal or subcutaneous injection of therapeutic agents in little dosages by the use of very fine needles to induce local effects (5).

Modulation of the pharmacokinetics of the injected material and to extend the pharmacological properties at a local sites is the aim of this sort of administration. Obtaining the local pharmacological outcome without the need for high systemic concentrations is considered one of the key advantages of mesotherapy (6).

To our knowledge this study is the first study to be done in Egypt to evaluate the potential effect of the mesotherapy in treatment of tender points in primary fibromyalgia patients.

\section{Patients and methods:}

Thirty PFM patients fulfilled the American Colleague of Rheumatology 1990 criteria, were enrolled into this study (7). They were recruited from the outpatient's clinic and inpatient's department of the Rheumatology, Rehabilitation and physical medicine Benha University hospitals from October 2019 to January 2020. 
Ethical considerations: An informed written consent was obtained from all participants prior to the study. This work was agreed by the Ethical Medical Committee of Benha University faculty of medicine.

Exclusion criteria: patients' age less than 16 years, pregnant and lactating females, patients with any systemic disease, like kidney or liver disease, cardiovascular disease, diabetes, hypothyroidism, infections, peptic ulcer, autoimmune disease, active skin lesions in the treated area, epileptic patients, patients receiving aspirin therapy or other anti-inflammatory medications and those with tendency to bleed, patients with known hypersensitivity to the used preparations and patients receiving other treatment of fibromyalgia (Physiotherapy or Drugs) for at least 2 weeks, Patients who take any medications that interact with the action of ketoprofen.

Patients were randomly classified into 2 groups according to the received program: Group I (15 patients) who received a mixture of $2 \mathrm{ml}$ of Ketoprofen $100 \mathrm{mg} / 2 \mathrm{ml}$ added to $3 \mathrm{ml}$ of Saline Solution via injection mesotherapy, once a week for 6 successive weeks (a total of 6 sessions). Group II (15 patients) who received Ketoprofen 100 mg Extended- Release capsules once daily for 2 successive weeks.

Full history taking and clinical examination were performed. Assessment of pain, quality of life (QoL) and depression using; VAS, fibromyalgia impact questionnaire (FIQ) and Hamilton Depression Rating Scale (HDRS) respectively ; at the start , after the $3^{\text {rd }}$ and $6^{\text {th }}$ cession treatment.

The FIQ consists of 10 items. 11 questions are included in the first item which is related to physical functioning (8).

\begin{tabular}{|c|c|c|c|c|}
\hline Variable & Item & Score & Range & Normalization \\
\hline Physical & 1 & No & $0-3$ & $\mathrm{~S} \times 3.33$ \\
\hline impairment & 2 & Yes & $0-7$ & $\mathrm{~S} \times 134$ \\
\hline Feel good & 3 & No & $0-7$ & $\mathrm{~S} \times 3.33$ \\
\hline Work missed & 4 & No & $0-10$ & None \\
\hline Do work & 5 & No & $0-10$ & None \\
\hline Pain & 6 & No & $0-10$ & None \\
\hline Fatigue & 7 & No & $0-10$ & None \\
\hline Rested & 8 & No & $0-10$ & None \\
\hline Stiffness & 9 & No & $0-10$ & None \\
\hline Anxiety & 10 & No & $0-10$ & None \\
\hline Depression & & & & \\
\hline
\end{tabular}

The greater the score, the greater the impact of the syndrome. The maximum possible score of each of the 10 items is 10. Thus, 100 is the maximum possible score. Usual score for FM patient is about 50, and score more than 70 
indicates severely afflicted patients usually. To obtain a total score of 100 , if a patient does not answer all 10 items, it is essential to use an 'equalization calculation'. In case of one or more than one item is missed, the last collective score required to be multiplied by $10 / \times$ [e.g. multiply by $10 / 9$ if one question is missed, (i.e. 1.111); multiply by10/8, if two questions are missed (i.e. 1.25)].

\section{Hamilton Rating Scale for depression}

This original version includes 17 items on symptoms of depression experienced over the last week. A five-point scale was used to score eight items, with range from 0 to 4 , with 0 representing not present and 4 representing severe. The remaining nine items were scored from 0 to 2. Normal scores ranges from 0-7; mild depression from 8-13; moderate depression from 14-18; severe depression from 19-22; and 23 or more indicate very severe depression (9).

Procedure: The practical part of the study was done at the mesotherapy unit in Rheumatology, Rehabilitation \& physical medicine department at Benha University hospitals.

Patient sat in a comfortable position according to the site to be injected, the treatment protocol was explained to the patient, the skin was prepared using proper hygiene, aseptic technique.

Single intradermal injection in each tender point was done using 5cc syringe with Specific needle positioned at 3045 degree. In general, $0.10-0.20 \mathrm{~mL}$ of product was injected in each point. Needle type: sterile, disposable intradermal needle, Lebel's needle (length $6 \mathrm{~mm}$, caliber 27), mild pressure with a piece of cotton was applied to the site after injection to prevent blood oozing. Patients were observed for few hours following the injection for any adverse effects.

\section{Statistical analysis}

A computer program SPSS (Statistical package for social science) version 20 (Chicago. Ill. USA) was used. Descriptive statistics were calculated for the data in the form of: Mean and standard deviation. To compare mean of two groups of quantitative data of parametric and non-parametric respectively, Student's t-test and MannWhitney test were used Paired test and Wilcoxon test: Used to compare mean of variables in different time periods of quantitative data of parametric and non-parametric respectively. Inter-group comparison of 
categorical data was performed by using chi square test $\left(\mathrm{X}^{2}\right.$-value $)$ and fisher exact test (FET).

$P$ values less than 0.05 were considered to indicate statistical significance $(*)$ while $\mathrm{P}$ values more than 0.05 was statistically insignificant and $\mathrm{P}$ value less than 0.001 was considered highly significant $(* *)$.

\section{Results:}

All subjects included in this study were females (100\%) whose mean age was $36.3 \pm 8.8$ years (24-51 years), BMI was $27.14 \pm 3.94$ and their disease duration was $5.14 \pm 4.1$ years.

Comparisons between group I and group II regarding the number of fibromyalgia tender points before and after treatment are shown in Table (1).

There were statistically significant differences $(\mathrm{P}<0.01)$ regarding the frequency of fibromyalgia tender points between group I and group II at the end of the study.

Table (2) shows Comparisons between group I and group II regarding VAS before and after treatment

A statistically highly significant difference $(\mathrm{P}<0.001)$ was reported as regards the VAS between group I and group II at the end of the study.
Table (3) shows Comparisons between group I and group II regarding FIQ before and after treatment

There was statistically highly significant difference $\quad(\mathrm{P}<0.001)$ regarding the FIQ between group I and group II at the end of the study.

Table (4) shows Comparisons between group I and group II regarding HDRS before and after treatment

Highly significant difference $\quad(\mathrm{P}<0.001)$ regarding the HRS between group I and group II post treatment was observed.

No major adverse effects were observed among group (I) patients after receiving mesotherapy injection; Pain was reported in 14 cases $(86.66 \%)$ which had resolved spontaneously or after cold fomentations, bruises was observed in 9 patients $(60 \%)$ and disappeared in one week spontaneously, Swelling and edema were observed in 8 patients $(53.3 \%)$ and relived spontaneously or by cold fomentation and comfort cotton clothes, transient urticaria was observed in 3 patients (20\%) relieved by topical steroids. 
Table (1): Comparisons between group I and group II regarding the number of fibromyalgia tender points before and after treatment

\begin{tabular}{|c|c|c|c|c|c|c|}
\hline & $\begin{array}{l}\text { Group I } \\
\text { No.=15 }\end{array}$ & $\%$ & $\begin{array}{l}\text { Group II } \\
\text { No.=15 }\end{array}$ & $\%$ & $\begin{array}{l}\text { Statistical test } \\
\text { (FET) }\end{array}$ & $P$ value \\
\hline Rt. occiput before & 8 & 53.3 & 8 & 53.3 & 0.0 & 1.0 \\
\hline Rt. occiput after & 2 & 13.3 & 5 & 33.3 & 2.54 & $0.01 *$ \\
\hline Lt occiput before & 7 & 46.7 & 8 & 53.3 & $\mathrm{X} 2=0.133$ & 0.715 \\
\hline Lt. occiput after & 2 & 13.3 & 6 & 40.0 & $X 2=5.4$ & $0.02 *$ \\
\hline Rt. Low cervical before & 6 & 40.0 & 6 & 40.0 & $\mathrm{X} 2=0.0$ & 1.0 \\
\hline Rt. Low cervical after & 2 & 13.3 & 5 & 33.3 & 1.53 & $0.021 *$ \\
\hline Lt. Low cervical before & 6 & 40.0 & 6 & 40.0 & $\mathrm{X} 2=0.0$ & 1.0 \\
\hline Lt. Low cervical after & 2 & 13.3 & 6 & 40.0 & 1.53 & $0.031 *$ \\
\hline Rt.trapezius before & 15 & 100 & 15 & 100 & - & - \\
\hline Rt.trapezius after & 1 & 6.7 & 12 & 80.0 & $\mathrm{X} 2=30.0$ & $<0.001 * *$ \\
\hline Lt.trapezius before & 15 & 100 & 15 & 100 & - & - \\
\hline Lt.trapezius after & 2 & 13.3 & 11 & 73.3 & $\mathrm{X} 2=30.0$ & $<0.001 * *$ \\
\hline Rt. Supra spinatus before & 15 & 100 & 15 & 100 & - & - \\
\hline Rt. Supra spinatus after & 1 & 6.7 & 10 & 66.7 & $\mathrm{X} 2=30.0$ & $<0.001 * *$ \\
\hline Lt. Supra spinatus before & 15 & 100 & 15 & 100 & - & - \\
\hline Lt. Supra spinatus after & 0 & 0.0 & 13 & 86.7 & $X 2=30.0$ & $<0.001 * *$ \\
\hline Rt. 2nd rib before & 7 & 46.7 & 6 & 40.0 & $\mathrm{X} 2=0.136$ & 0.713 \\
\hline Rt. 2nd rib after & 1 & 6.7 & 4 & 26.7 & 0.64 & $0.04 *$ \\
\hline Lt. 2nd rib before & 7 & 46.7 & 7 & 46.7 & $\mathrm{X} 2=0.0$ & 1.0 \\
\hline Lt. 2nd rib after & 2 & 13.3 & 5 & 33.3 & 2.54 & $0.01 *$ \\
\hline $\begin{array}{l}\text { Rt. Lateral humeral epicondyle } \\
\text { before }\end{array}$ & 15 & 100 & 15 & 100 & - & - \\
\hline $\begin{array}{l}\text { Rt. Lateral humeral epicondyle } \\
\text { after }\end{array}$ & 2 & 13.3 & 9 & 60.0 & $X 2=30.0$ & $<0.001 * *$ \\
\hline $\begin{array}{l}\text { Lt. Lateral humeral epicondyle } \\
\text { before }\end{array}$ & 15 & 100 & 15 & 100 & - & - \\
\hline $\begin{array}{l}\text { Lt. Lateral humeral epicondyle } \\
\text { after }\end{array}$ & 4 & 26.7 & 12 & 80.0 & $\mathrm{X} 2=30.0$ & $<0.001 * *$ \\
\hline Rt. Gluteal before & 15 & 100 & 15 & 100 & - & - \\
\hline Rt. Gluteal after & 2 & 13.3 & 11 & 73.3 & $\mathrm{X} 2=30.0$ & $<0.001 * *$ \\
\hline Lt. Gluteal before & 15 & 100 & 15 & 100 & - & - \\
\hline Lt. Gluteal after & 4 & 26.7 & 8 & 53.3 & $\mathrm{X} 2=30.0$ & $<0.001 * *$ \\
\hline Rt. Greater trochanter before & 15 & 100 & 15 & 100 & - & - \\
\hline Rt. Greater trochanter after & 1 & 6.7 & 7 & 46.7 & $\mathrm{X} 2=30.0$ & $<0.001 * *$ \\
\hline Lt. Greater trochanter before & 15 & 100 & 15 & 100 & - & - \\
\hline Lt. Greater trochanter after & 1 & 6.7 & 10 & 66.7 & $X 2=26.25$ & $<0.001 * *$ \\
\hline Rt. Knee before & 15 & 100 & 15 & 100 & - & - \\
\hline Rt. Knee after & 3 & 20.0 & 10 & 66.7 & $\mathrm{X} 2=30.0$ & $<0.001 * *$ \\
\hline Lt. Knee before & 15 & 100 & 15 & 100 & - & - \\
\hline Lt. Knee after & 4 & 26.7 & 12 & 80.0 & $\mathrm{X} 2=30.0$ & $<0.001 * *$ \\
\hline
\end{tabular}


RT.: Right, LT.: Left

Table (2): Comparisons between group I and group II regarding VAS before and after treatment

\begin{tabular}{|c|c|c|c|c|}
\hline & Group I (mean \pm SD) & Group II $($ mean \pm SD) & Statistical test (st t) & $P$ value \\
\hline VAS before & $8.33 \pm 1.23$ & $8.07 \pm 0.96$ & 0.66 & 0.52 \\
\hline VAS $3^{\text {rd }}$ & $5.53 \pm 1.06$ & - & & \\
\hline $\begin{array}{lll}\text { VAS } & \text { after } & 6^{\text {th }} \\
\text { dose } & & \end{array}$ & $1.87 \pm 0.92$ & $6.07 \pm 0.96$ & 18.09 & $<0.001 * *$ \\
\hline
\end{tabular}

VAS: Visual analogue scale.

Table (3): Comparisons between group I and group II regarding FIQ before and after treatment

\begin{tabular}{lllll}
\hline & Group I $($ mean \pm SD $)$ & Group II $($ mean \pm SD $)$ & Statistical test $($ st t $)$ & P value \\
\hline FIQ pre & $62.0 \pm 12.36$ & $64.67 \pm 9.73$ & 0.66 & 0.52 \\
FIQ 3 $^{\text {rd }}$ & $52.6 \pm 11.71$ & - & & \\
FIQ after 6 $^{\text {th }}$ dose & $41.67 \pm 11.31$ & $60.4 \pm 9.98$ & 4.81 & $<0.001^{* * *}$ \\
\hline
\end{tabular}

FIQ: Fibromyalgia impact questionnaire.

There was statistically highly significant difference $(\mathrm{P}<0.001)$ regarding the FIQ between group I and group II at the end of the study.

Table (4): Comparisons between group I and group II regarding HDRS before and after treatment

\begin{tabular}{|c|c|c|c|c|c|}
\hline & $\begin{array}{l}\text { Group I } \\
\mathbf{N}(\%)\end{array}$ & $\begin{array}{l}\text { Group II } \\
\mathbf{N}(\%)\end{array}$ & $\begin{array}{l}\text { Statistical } \\
\text { (FET) }\end{array}$ & test & $P$ value \\
\hline \multicolumn{6}{|l|}{ HDRS pre } \\
\hline mild & 0 & 0 & & & \\
\hline Moderate & $5(33.3)$ & $2(13.3)$ & 1.94 & & 0.42 \\
\hline Severe & $5(33.3)$ & $8(53.3)$ & & & \\
\hline Very severe & $5(33.3)$ & $5(33.3)$ & & & \\
\hline \multicolumn{6}{|l|}{ HDRS $3^{\text {rd }}$} \\
\hline Mild & $4(26.7)$ & - & & & \\
\hline Moderate & $8(53.3)$ & & & & \\
\hline Severe & $3(20.0)$ & & & & \\
\hline $\begin{array}{l}\text { Very severe } \\
\text { HDRS after } 6^{\text {th }}\end{array}$ & 0 & & & & \\
\hline
\end{tabular}




\begin{tabular}{|c|c|c|c|c|}
\hline Normal & $5(33.3)$ & $0(0.0)$ & 20.44 & $<0.001 * *$ \\
\hline Mild & $8(53.3)$ & $1(6.7)$ & & \\
\hline Moderate & $2(13.3)$ & $5(33.3)$ & & \\
\hline Severe & $0(0.0)$ & $7(46.7)$ & & \\
\hline Very severe & $0(0.0)$ & $2(13.3)$ & & \\
\hline
\end{tabular}

HDRS: Hamilton depression rating scale

\section{Discussion}

Fibromyalgia is defined as a chronic , non-articular pain syndrome of unknown etiology, characterized by widespread musculoskeletal pain associated with numerous painful points (10). The prevalent usage of "alternative" treatments is related to the increased incidence of adverse events related to NSAIDs [6]. In this regard, Mesotherapy has been suggested as a treatment for pain relief in musculoskeletal diseases; where the site of injection is located at the site of the pathological condition (11).

In the current study, regarding the frequency of fibromyalgia tender points and the sensitivity of pain measured by VAS; there were statistically significant differences $(\mathrm{P}<0.01)$ between group I and group II at the end of the study. Our results go hand in hand with Bárbara et al. (12) who injected small quantities of intradermal drug, lidocaine $2 \%$, in painful tender points in FM patients and concluded that the therapeutic effect of the mesotherapy was satisfactory in achieving a reduction of the painful points with a very significant stocking at the end of the treatment, as well as a decrease in the functional inability being the time of remission of smaller pain and similar to 6 sessions.

This may be explained as the needle injected at the painful site stimulates the cutaneous and subcutaneous receptors (reflex arc), with subsequent increase in endorphin levels. Moreover, in the dermis the microvascular system and the immune cells interact together which may in turn produce clinical benefits (13).

Since the studies of mesotherapy as a treatment modality for fibromyalgia is very scarce, we compared our results to other musculoskeletal disorders of chronic nature.

Other studies used different cocktails of mesotherapy solutions to prove the efficacy of mesotherapy as a modality for pain management in chronic pain disorders. 
Our results coincide with the previous study done.(14) where mesotherapy (lidocaine hydrochloride 2\% ) was used as a modality for chronic neck pain treatment and with another study performed using lysine acetylsalicylate in treatment of patients complained of low back pain.(15) They reported significant improvements in patients compared to the control group

The efficacy of mesotherapy was proved in treatment of rotator cuff tendinopathy using injectable cocktail included NSAIDs, a coumarin derivative, procaine, and sometimes associated with a vasodilator. Results showed that $80.7 \%$ reported objective improvement of pain or of ROM. (16)

It was suggested that disodium EDTA administered by both mesotherapy and phonophoresis would be used as physiotherapy as a treatment modality for calcific tendinitis of the shoulder joint as it was safe, effective in decreasing pain, enhancing shoulder function, and eliminating calcifications. (17)

Chen et al (18) and Saggini et al (19) used other mesotherapy cocktails in treatment of knee osteoarthritis patients and patients with pes anserinus bursitis respectively and reported an improvement in pain and function.
However, in a study, in which eighty four participants complained of acute low back pain were subjected to treatment with either oral and intramuscular drug administration $(n=42)$ or administration of NSAIDs and corticosteroids by mesotherapy $(n=42)$, results showed that both groups improved, with no significant difference in reduction of subjective pain (as assessed by VAS) between the two groups. (20)

In our study we used only one drug which proved its efficacy in treatment of fibromyalgia tender points. Others used mixture of medications that augment the risk of drug-drug interactions, even if two active drugs, specially lidocaine and NSAIDs have been stated to be safe. Furthermore, using mixtures of drugs, it is difficult to recognize the effects of separate drugs with regarding the effectiveness and tolerability. A mixture of NSAIDs and anesthetics, was once used (19) while a combination of steroid and anesthetic was used in another study (21) Single drug seems to decrease the risk of pharmacological interactions and local adverse reactions (13).

Numerous studies reported increased incidence of psychiatric disorders in fibromyalgia patients compared with the general population (22). In our PFM patients, $73.3 \%$ of our patients suffered from 
depression which together with chronic pain and fatigue affects patient's life; the treated patients with injection mesotherapy showed significant improvements in their HDRS and FIQ before and at the end of the study

As regard adverse reactions of mesotherapy injection, in our study we recorded few adverse reactions in the form of Pain (93.3 $\%)$, bruises $(60 \%)$, redness $(100 \%)$, edema $(53.33 \%)$, transient urticaria $(20 \%)$. These results go hand in hand with other studies (23) and (24), who reported injection site adverse effects included tenderness, edema, hematoma (bruising), numbness, redness, induration, paresthesia, and nodule after subcutaneous injection of deoxycholic acid used for reduction of submental fat, they were mild or moderate in severity, transient in nature, and resolved without interventions.

Similarly, it was observed that also abrupt side effects like swelling, redness, and pain, that disappeared within hours (24). Although ecchymosis, and paresthesia take days or weeks to resolve, , mild or very mild systemic side effects like nausea, diarrhea, dizziness, light headache and inter-menstrual bleeding were reported.(25)

Some more severe adverse events after mesotherapy injection, including mycobacterial infection, koebnerization of psoriasis, urticaria pigmentosa, subcutaneous nodules, drug eruptions and hyperpigmentation, were reported (26). In another study, it was that an outbreaks of rapidly growing mycobacteria, an occurrence of cutaneous abscesses following mesotherapy injection due to infection with Mycobacterium chelonae, does happen (27) .

\section{Conclusion:}

This study support the hypothesis that injection mesotherapy might offer a satisfying results in treatment of fibromyalgia tender points thus it represents an alternative therapeutic technique especially in the presence of associated comorbidities where there is a high risk of drug interaction, polypharmacy, or when conventional (oral or parenteral) NSAIDs use is contraindicated.

We recommend also using other different cocktails of mesotherapy solutions to prove the efficacy of this technique as a therapy of other rheumatic diseases.

However, here are some limitations to our study, which are the small number of patients and the lack of comparison of mesotherapy to other lines of FM treatment.

\section{Acknowledgements:}

The author thanks Prof. Refaat M. E., Prof. Sahar S. G. and Ass. Prof. Rasha F. M. professors of Rheumatology, 
Rehabilitation and physical medicine, Faculty of Medicine, Benha University for their supervision, endless support, encouragement and great assistance..

\section{References}

1- Rodríguez-Pintó I, Agmon-Levin N , Amital H , Shoenfeld Y. .Fibromyalgia and Cytokines. Immunology letters. 2014; 161, (2), 200-203.

2- Lindsay M, Craig M , Jane S. The potential benefits of applying a narrative analytic approach for understanding the experience of fibromyalgia: a review, Disability and Rehabilitation.2012; 34(13): 1121-1130.

3- Enrico B, Eleonora M, Filippo C, Nicola B, Lorenzo M, Davide E B et al. "Fibromyalgia Syndrome: Etiology, Pathogenesis, Diagnosis, and Treatment," Pain Research and Treatment. 2012; Pain Research and Treatment Volume 2012, 1-17.

4- Pistor M. "What is mesotherapy?" Le Chirurgien-Dentiste de France. 1976 ; 46, (288), 59-60.

5- Paolucci T, Bellomo RG, Centra MA, Giannandrea N, Pezzi L, Saggini R. Mesotherapy in the treatment of musculoskeletal pain in rehabilitation: the state of the art. J Pain Res. 2019 ;12:23912401.

6- Mammucari M, Gatti A, Maggiori S, Sabato AF. Role of mesotherapy in musculoskeletal pain: opinions from the italian society of mesotherapy. Evid Based Complement Alternat Med.;2012: Volume 2012, 1-12.

7- Wolfe F, Smythe HA, Yunus MB, Bennett RM, Bombardier C, Goldenberg DL. et al. The American College of Rheumatology 1990 Criteria for the
Classification of Fibromyalgia: report of the Multicenter Criteria Committee. Arthritis Rheum.,1990, 33:160-72.

8- Burckhardt CS, Clark SR, Bennett RM. The fibromyalgia impact questionnaire: development and validation. J Rheumatol ; 1991: 18:728-33.

9- Hamilton M. A rating scale for depression. J Neurol Neurosurg Psychiatry 1960; 23:5662.

10-Di Franco M, Iannuccelli, C, Valesini, G. Neuroendocrine immunology of fibromyalgia. Ann. N.Y. Acad. Sci. 2010, 1193; 84-90.

11-Maggiori S. Manuale di Intradermoterapia Distrettuale. La Mesoterapia in Italia, EMSI, Roma, Italy, 2004.

12- Bárbara $S$ R, Isabel $M \quad C$. "Mesotherapy in patients with fibromyalgia." Revista Cubana de Reumatología 2012:14.20.

13-Mammucari M, Gatti A, Maggiori S, Bartoletti CA, Sabato AF. Mesotherapy, definition, rationale and clinical role: a consensus report from the Italian Society of Mesotherapy. Eur Rev Med Pharmacol Sci. 2011;15(6):682-694.

14-Paolucci T, Piccinini G, Trifan PD, Zangrando F, Saraceni VM. Efficacy of Trigger Points Mesotherapy for the Treatment of Chronic Neck Pain: A Short Term Retrospective Study. Int J Phys. 2016; 2: 113.

15-Ciotti C, Laurini A, Tiberti S, Foti C. Lumbar Mesotherapy in the treatment Of Low Back Pain. 9th Mediterranean Congress of PRM 40th National Congress. Simfer. Giornale Italiano Di Medicina Riabilitativa. 2012; 26 (2-3).

16-Sposito MM, Rivera D, Riberto M, Metsavaht L. Mesotherapy improves range of 
motion in patients with rotator cuff tendinitis. Acta Fisiatr. 2011; 18(4): 196 - 199.

17-Cacchio A, De Blasis P, Desiati G, Spacca V, Santilli F, De Paulis. Effectiveness of treatment of calcific tendinitis of the shoulder by disodium EDTA, Arthritis Care and Research, 2009; (61) 1, 84-91.

18-Chen L, Li D, Zhong J, Qiu B, Wu X. Therapeutic effectiveness and safety of mesotherapy in patients with osteoarthritis of the knee. Evidence-Based Compl Altern Med. 2018;4: 6513049 .

19-Saggini R, Di Stefano A, Dodaj I, Scarcello L, Bellomo RG. Pes anserine bursitis in symptomatic osteoarthritis patients: a mesotherapy treatment study.J Altern Compl Med. 2015;21(8):480-484.

20-Costantino C, Marangio E, Coruzzi G. Mesotherapy versus systemic therapy in the treatment of acute low back pain: a randomized trial, $\quad$ Evidence-Based Complementary and Alternative Medicine, 2011, Article, 1-6. Article ID 317183.

21-Yang $X$, Geng Z, Zhang XL, Zhang YH, Wang $X$, Zhang XB. et al. Single intracutaneous injection of local anesthetics and steroids alleviates acute nonspecific neck pain: A CONSORT-perspective, randomized, controlled clinical trial. Medicine (Baltimore). 2018;97(28).

22-McBeth J, Silman AJ. The role of psychiatric disorders in fibromyalgia. Curr. Rheumatol. Reports., 2001; 3(2):157-164.

23-Ascher B, Fellmann J, Monheit G. ATX-101 (deoxycholic acid injection) for reduction of submental fat. J. Expert Review of Clinical Pharmacology; 2016; 9(9): 1131-1143.

24-El Kamshoushy A, Abel Maksoud R, El Mahdy N. Evaluation of the Efficacy of Injection Lipolysis using Phosphatidylcholine/Deoxycholate Versus Deoxycholate Alone in Treatment of Localized Fat Deposits. J Clin Exp Dermatol Res, 2012; 3:146.

25-Palmer M, Curran J, Bowler P. Clinical experience and safety using phosphatidylcholine injections for the localized reduction of subcutaneous . 2006. Journal of Cosmetic Dermatology, 5, 218-226.

26-Rotunda AM, Avram MM, Avram A. Cellulite: is there a role for injectable? $\mathrm{J}$ Cosmet Laser Ther;2005; 7 :147-154.

27-Munayco CV, Grijalva CG, Culqui DR, José L B. Outbreak of Persistent Cutaneous Abscesses Due to Mycobacterium Chelonae After Mesotherapy Sessions, Lima, Peru. Rev Saude Publica; 2008, 42 (1): 146-149.

To cite this article: Refaat M. Eltanawy, Sahar S. Ganeb, Rasha M. Fawzy, Samia O. Ghorab Effectiveness Of Mesotherapy In Treatment Of Fibromyalgia Tender Points. BMFJ2020;37(1): 285296. DOI:10.21608/bmfj.2020.27913.1247 